\title{
EL FUEGO DE SAN ANTONIO: ESTUDIO DEL ERGOTISMO EN LA PINTURA DEL BOSCO
}

\author{
Isabel Morán Suárez \\ Historiadora del Arte - C/ Ronda de Atocha, 10 - 4. ${ }^{\circ}$ B. 28012 Madrid
}

\section{RESUMEN}

Estudio de la epidemia medieval del ergotismo en la pintura del Bosco y su escuela. Etiología, terapéutica de la enfermedad y su repercusión socio-artística.

\begin{abstract}
Study of the Medieval Epidemy of Ergotism through the Bosch's Paintings and other Iconography. Etiology, Therapy and social-artistic effects.
\end{abstract}

La Europa que discurre entre los años 1450-1520 es el fiel reflejo de un continente vacío y pesimista, sacudido por epidemias, hambres y cuyo semblante lo perfila la muerte. En dicho contexto se desarrolla la obra pictórica de Hieronymus Bosch. El Bosco (Blois-le-Duc, 1450?-1516) nace precisamente en el tránsito de dos épocas, en un momento plagado de desconcierto. Dentro de la producción del pintor flamenco, amplia y de controvertida interpretación, he hallado ejemplos (algunos inéditos) cuyas figuras pueden captar el interés del estudioso de la medicina popular medieval.

Aunque es difícil, y ambiguo al mismo tiempo, determinar (por simple apreciación) las causas de la deformidad física que dichas figuras representadas en los siguientes cuadros presentan, si creo posible establecer una conexión coherente entre los personajes enfermos, su santo sanador, y la enfermedad que curaba bajo su advocación y que tantas vidas se cobró: el ergotismo o, como popularmente se le denominó, «Fuego de San Antonio».

El punto de partida lo constituye el dibujo preparatorio que el Bosco realiza bajo el título de Mendigos y Tullidos conservado en el Gabinete de Estampas de la Biblioteca Real de Bruselas (fig. 1). En el dibujo autógrafo, el Bosco expone una diversidad de lisiados, cuyas piernas o brazos aparecen visiblemente mutilados y deformados. Apoyados en soportes de madera, vemos cómo los más afortunados mantienen su dignidad humana erecta, mientras que los más desdichados, se arrastran larvaria- 


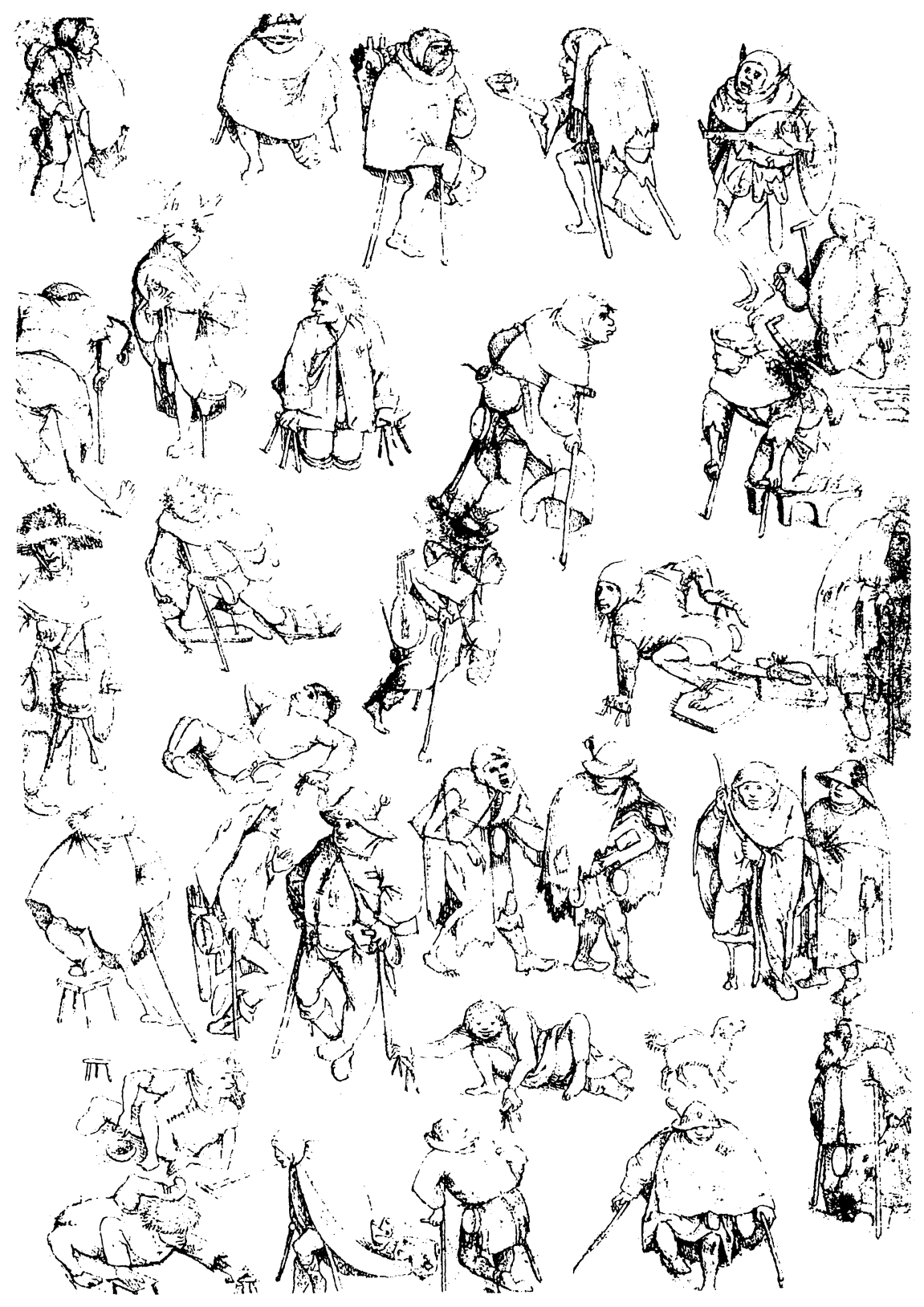

Fig. 1.- Dibujo autografo del Bosco Mendigos y Tullidos Gabinete de Estampas, Biblioteca Real de Bruselas. 
mente. Abocados a la mendicidad o a la supervivencia mediante la música, representan un claro ejemplo de los estragos de las enfermedades finiseculares en Europa.

El estudio que el Bosco realiza en este dibujo sirve de modelo a posteriores obras que imitan sus inválidos y desmembrados. Me ceñiré a tres ejemplos que he seleccionado por parecerme elocuentes al respecto. El primero (fig. 2) trata del reverso de la tabla titulada Las tentaciones de San Antonio, del Museo des Valenciennes (Francia); representa al santo eremita orando en el umbral del monasterio, al que se acercan lisiados y tullidos en busca de su curación. En segundo lugar, la tabla anónima del siglo XVI de las Tentaciones de San Antonio también (fig. 3 ), que nos presenta, en el ángulo inferior izquierdo, a un personaje ciego acompañado de un perro y zanfoña. Es patente su mano espasmodizada (por las convulsiones), así como el blefarospasmo que padece y priva consecuentemente de visión al mendigo/enfermo que es conducido ante la presencia del santo para curarse. Finalmente, el tercer ejemplo lo constituye un tapiz de la escuela bruselense del siglo XVI titulado La marcha de San Antonio (fig. 4), y en el que el santo a caballo se abre paso delante de todos los enfermos y tullidos que ante él exhiben sus mutilaciones, con idéntico propósito de salvación.

Sobradamente son conocidos los estragos que la lepra causó en el siglo XII, cobrándose hasta 25.000 vidas, así como la mortifera peste negra que asoló Europa y gestó, en torno al pánico que provocaba, un tipo concreto de arte y literatura. La sífilis no se rezagó en disparar la mortalidad además de suscitar polémicas sobre su proveniencia. Dichas enfermedades eran entendidas a veces como maldiciones divinas y otras, como la consecuencia directa de una desviada conducta humana. En medio de estas pandemias bajomedievales, surge un brote epidémico conocido como el fuego de San Antonio (por ser éste el santo protector contra la enfermedad y, por extensión, contra los incendios).

Las fuentes más antiguas en las que se cita la enfermedad del Ignis Sacer, son las Geórgicas de Virgilio y el De Natura Rerum de Lucrecio. Ambas relacionan este Ignis Sacer con la erisipela, retomando los estudios que el rigor científico árabe ya había realizado al respecto. El ergotismo o ergotinismo es una enfermedad provocada por la ingestión, más o menos prolongada, del centeno contaminado por el hongo llamado claviceps Purpurea o cornezuelo. Los alcaloides del cornezuelo del centeno constituyen drogas de origen natural, procedentes del reino vegetal. De esta manera, el consumo del pan nocivo sería el causante inmediato y directo de la mortalidad.

Probablemente, dos serían los motivos que favoreciesen la contagiosa epidemia con celeridad: en primer lugar, el hecho que el centeno se estrojase mal por las altas condiciones de humedad y, en segundo lugar, que el consumo del pan nocivo fuera masivo ante las carestías del trigo ${ }^{1}$, afectando, de modo singular, a las clases social-

I Laín, P. (1972), Historia Universal de la Medicina. Tomo II: Edad Media, Barcelona, p. 347. 
ISABEL MORÁN SUÁREZ

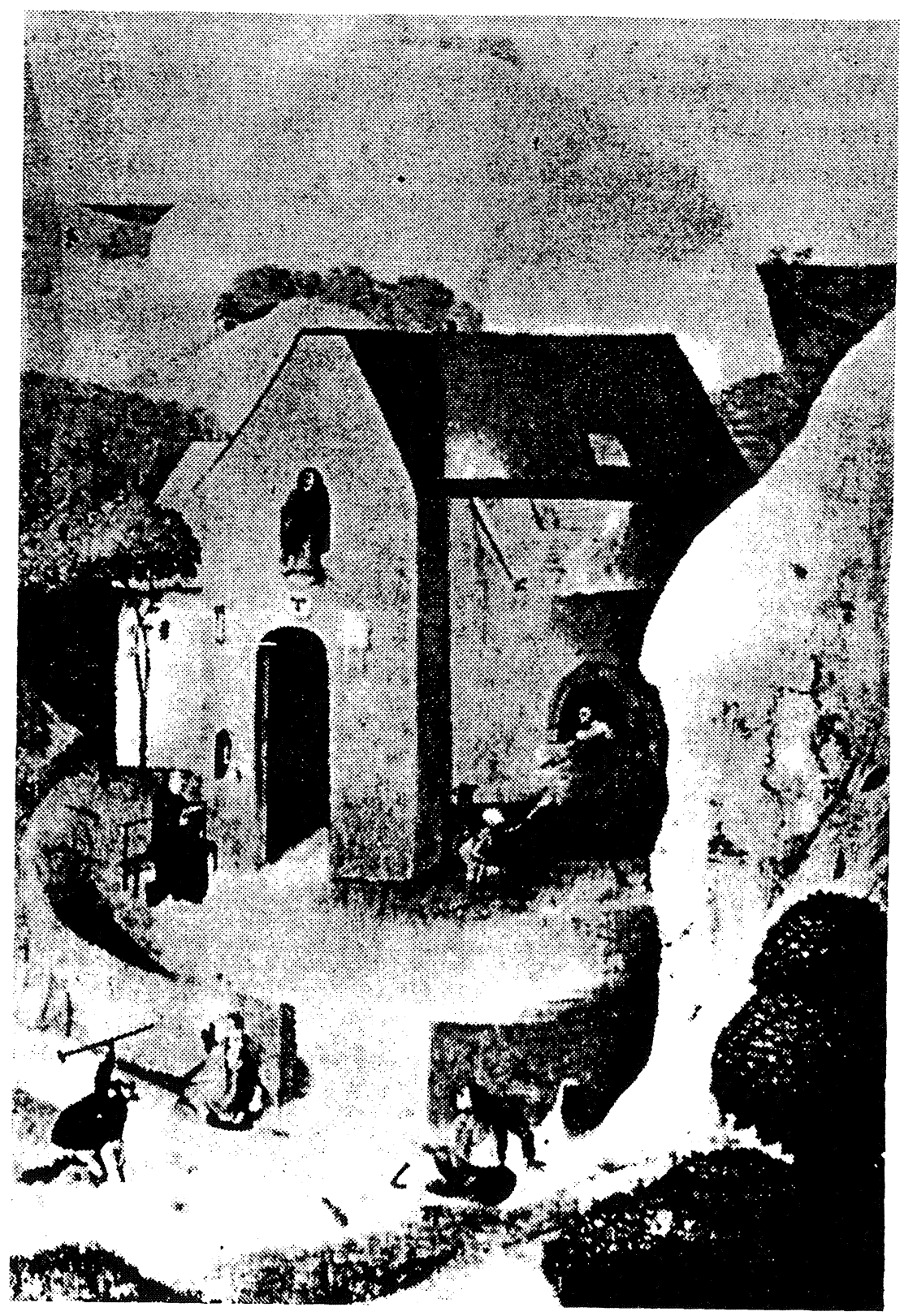

Fig. 2.- H. Bosch. Las Tentaciones de San Antonio. Musée des Valenciennes, Francia. 


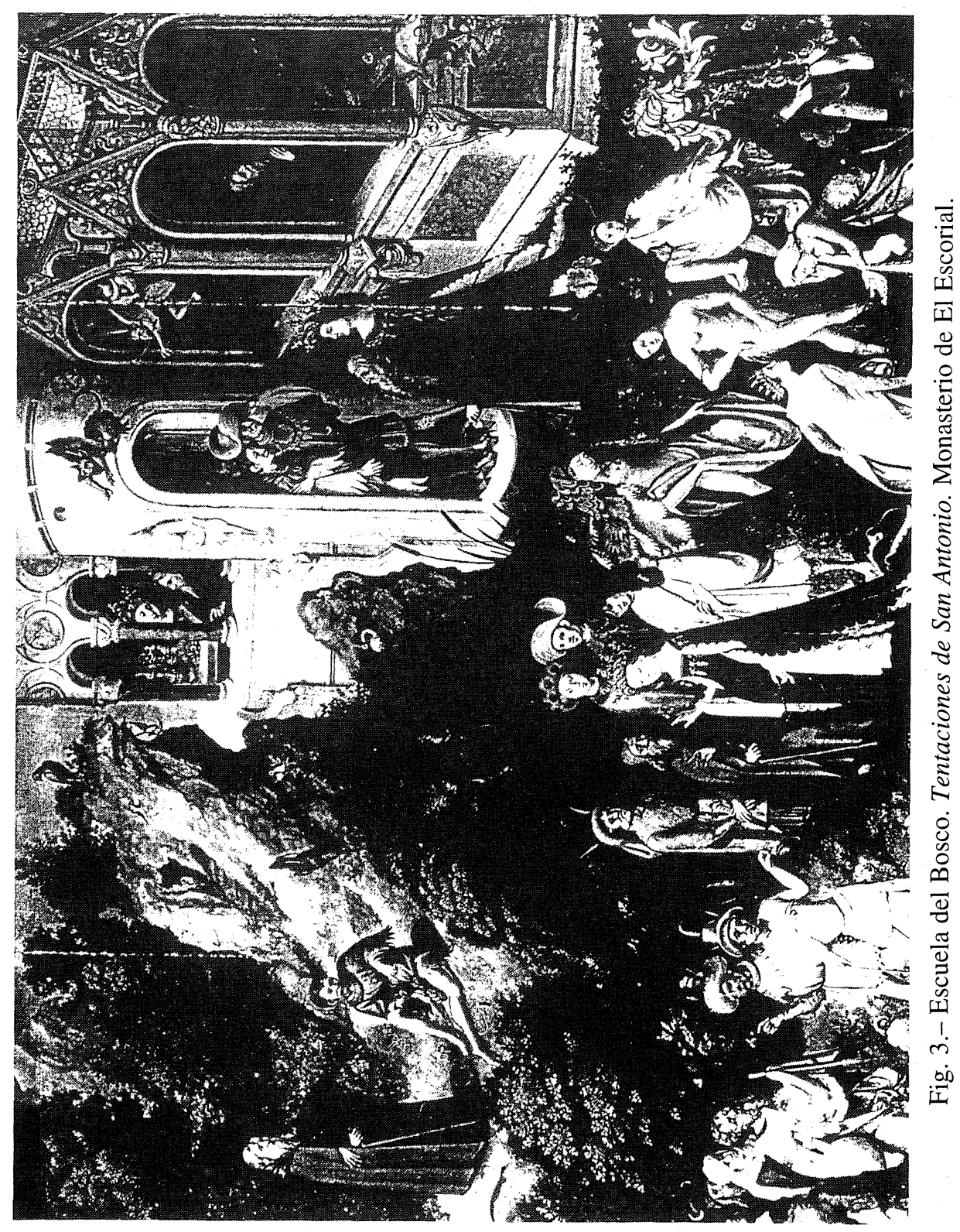




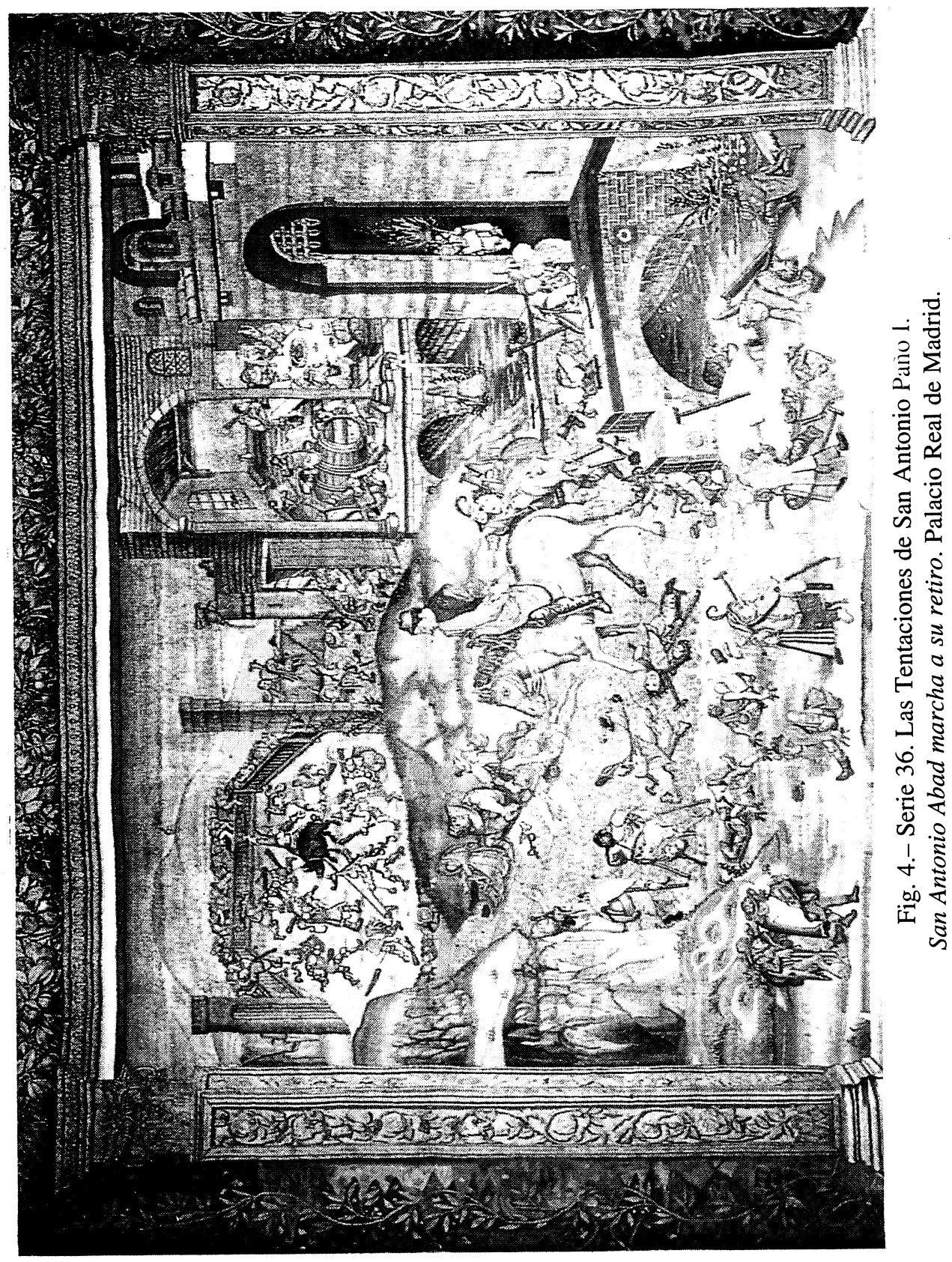


mente más deprimidas. Desasistidas e indigentes, se refugiaban en el culto de santos protectores, por medio de cuya intercesión creían curarse. Recordemos en este punto que la idea común durante la Edad Media de veneración a santos potencialmente sanadores, fraguó una iconografía específica que las artes plásticas testimonian . De la misma manera que se admitían las facultades de San Antonio para sanar a los afectados de ergotismo, San Severino curaba con su saliva a los leprosos y bajo las advocaciones de San Sebastián o San Roque, se podía conseguir vencer a la peste ${ }^{2}$. La fig. 5 nos ilustra de la iconografía de los santos protectores contra las plagas (en un sentido genérico) y que revela la importancia que adquirió el temor a las enfermedades contagiosas en las mentalidades y en el arte.

Este mal del fuego o mal de los ardientes, identificado con cuño propio y diferenciado de la peste ${ }^{3}$ presenta un cuadro clínico que se manifiesta de dos modos. A saber:

A) El ergotismo agudo, caracterizado por fuertes convulsiones espasmódicas en ambas extremidades, crisis epilépticas y parestesias. Durante las crisis convulsivas, el enfermo se movía incontroladamente; estos síntomas se prestaban a confusiones con otras patologías «danzantes», como señala el doctor Ortiz de Zárate, quien lo asemeja con el popular baile de San Vito o Corea Minor ${ }^{4}$. No obstante, parece mas lógico asociar el fuego de San Antonio con la enfermedad de Huntington o enfermedad de Brueghel, manifestada igualmente por fuertes crisis convulsivas. El origen de dichas convulsiones se encuentra en la cornutina, agente que ataca indiscriminadamente al sistema nervioso. El afectado recibía entonces el nombre de "contracto», debido a las contracciones que padecía. Dentro de esta modalidad, la muerte se podía producir por parálisis respiratoria.

B) El ergotismo crónico o mortal, efecto producido por la vasoconstricción periférica. La isquemia en piernas podía conducir a la gangrena, en cuyo proceso gangrenoso se registraban distonías, trombosis o vasculopatías periféricas en órganos como orejas, nariz y dedos. Este último síntoma ha equivocado a veces al ergotismo con la lepra, a pesar de que como Caracci demuestra en su estudio ${ }^{5}$ los leprosos estaban afectados 636-37

2 Grant, C. (1940), «Hagiological Healing», Bulletin of the History of Medicine. 3. 636-42; pp.

3 Brabant, H. (1967), Médecins Malades et Maladies de la Renaissance, Paris, pp. 89 y 91.

4 ORTIZ DE ZÁrATE, J. (1987), «La manía danzante, el fuego de San Antonio, la locura epidémica y el ergotismo», Revista de Neurología Argentina, 13, 268-76; p. 270.

5 CARACCI, P. (1972), «L'Iconografia del malato, mutilato dei piedi vuol sempre rappresentare il Lebbroso?», Pagine di Storia della Medicina, I6, 81-95; p. 90. 
en la cara (terminando, en último extremo, con la faz leonina) mientras que los enfermos de ergotismo presentaban principalmente sus secuelas en manos y pies. El efecto producido por la gangrena en las extremidades llevaba a dos inmediatas consecuencias: la necrosis del órgano afectado o la amputación de dicho órgano. A tales enfermos se les llamaba «desmembrados», «stropiat» o «Aliri» ${ }^{6}$, término inglés cuya etimología definía a los que tenían las piernas paralizadas. Los dolores de sus afectados debieron ser tan intensos, que el sentir popular los transformó en maldición. François Rabelais (1495-1553) nos la transmite, al exclamar Gargantúa : «Mal Fuego de San Antonio le queme la tripa cular al orfebre que las hizo y a la doncella que las llevaba.» ${ }^{7}$.

Finalmente, en todos los afectados por el ergotismo se registraba un síntoma común: la fiebre, tan elevada, que quienes la soportaban describían posteriormente visiones extrañas y alucinaciones. De este modo, el Ardiente, era el enfermo que sentia un inmenso calor en su cuerpo hasta el extremo de hallar en el grabado de Hans von Gersdorf (fig. 6) la transformación de la mano de un afectado por el fuego de San Antonio en llama viva. Los delirios recibieron el nombre de borrachera ergotínica, en cuyos efectos, algunos autores como Reau ${ }^{8}$ hallan el origen de las fantasías proyectadas en las Tentaciones del Santo. Conviene matizar que el término de «fuego» aplicado a los enfermos de ergotismo hace referencia a la excitación del sistema nervioso periférico, mientras que las alucinaciones se deben más bien a la excitación del sistema nervioso central. Recientes análisis han revelado que el ya citado hongo causante de la enfermedad del ergotismo (claviceps Purpurea) está próximo a la dietil amida del ácido lisérgico, sobradamente conocida por sus efectos alucinógenos ${ }^{9}$ : sin olvidarnos tampoco que el núcleo químico de estos alcaloides del centeno, son parecidos al LSD ${ }^{10}$. Acompañando a la alta temperatura, las convulsiones o la gangrena, hemos de añadir otros síntomas como sedación, hipotensión, vómitos, cefaleas, paraplejias, infartos de miocardio que configuran definitivamente el cuadro clínico.

Generalmente, las horrendas visiones producidas por la alta fiebre, eran descritas posteriormente, generando así una temática específica dentro del frenético culto hacia San Antonio. Este santo, nacido en Egipto (251-356), llevó un tipo de vida ascé-

6 Colledge, E. (1958), «Aliri», Medium Aevum, 27, 111-13; p. 112.

7 Rabelais, F. (1992), Gargantúa, Madrid, p. 85.

8 REAU, L. (1958), Iconographie de l'Art Chrétien, 3, París, 101-15; p. 104.

9 HAYUM, A. (1977), «The Meaning and Function of the Isenheim Alterpiece: the Hospital Context Revisited», The Art Bulletin, 49, 501-17; p. 516.

10 VelÁzQUeZ et Al. (16 ed. 1993), Farmacología clínica, Madrid, p. 149. 


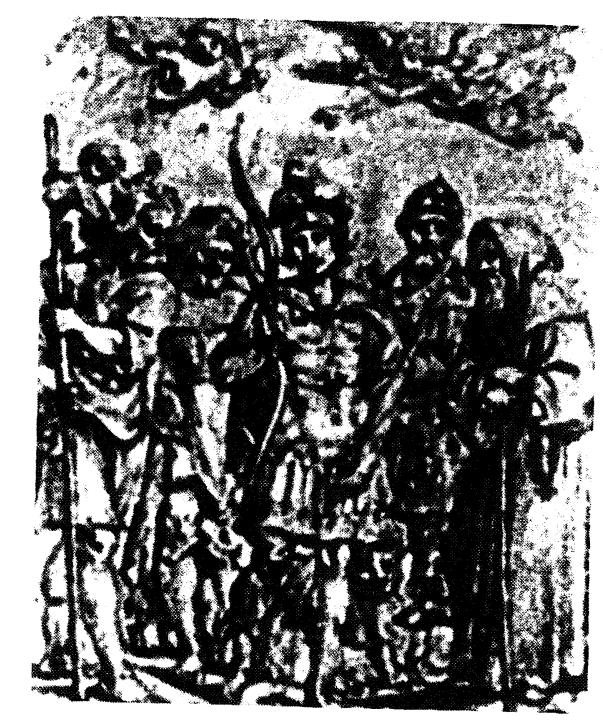

Fig. 5.- Pieter de Jode (S. XVII). Santos Protectores contra las Plagas. The Warburg Institute of London University. Archivo fotográfico.

Fig. 6.- Hans Von Gersdorf, 1517. Grabado de San Antonio el Grande. Feldbuch der Wundartznei.

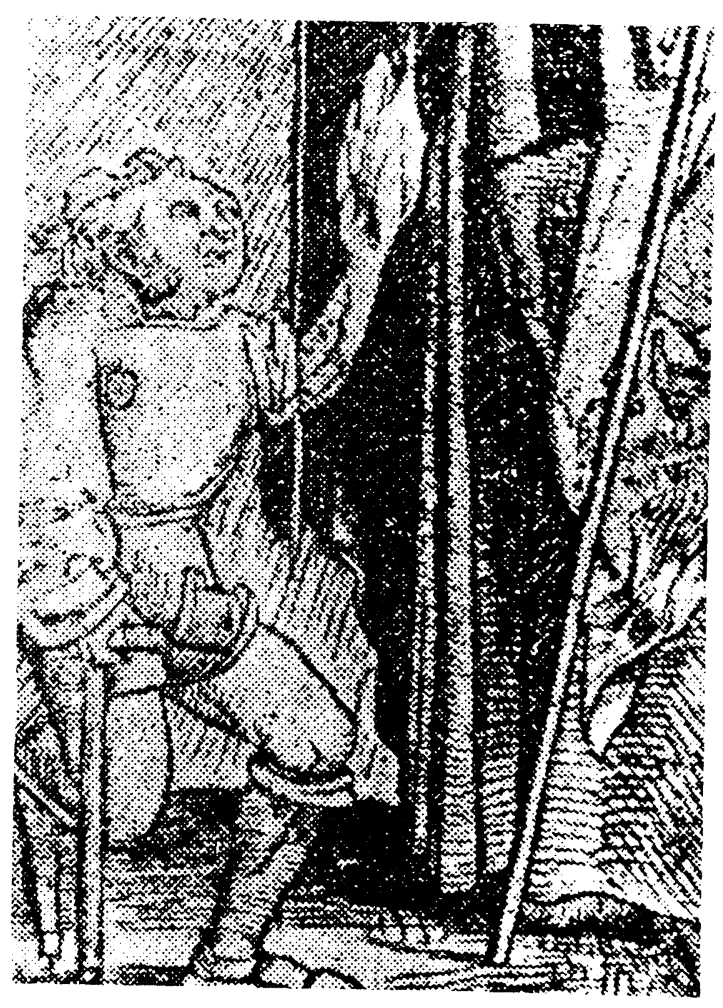


tica en el desierto, atribulado por las múltiples tentaciones que le acechaban. Al final de sus días, trancurridos en compañía de otro ermitaño, Pablo de Tebas, dejó establecidas las bases del monacato occidental, así como un modelo de vida eremítica. Su biografía, redactada por el obispo de Alejandría, San Atanasio, en su Vita Antonii en el 356 hace dudar de la historicidad del personaje pero, a pesar de lo verosímil o no de sus hechos, lo que parece irrefutable es el gran impacto que San Antonio ejerció tanto en la devoción popular medieval como en las manifestaciones artísticas ${ }^{11}$. Versiones apócrifas posteriores enriquecieron la vida del santo con diversas tentaciones y Jacopo de la Vorágine, apoyado en la Vitae Patrum, redactó su Leyenda dorada en el año 1478, cuya biografía de San Antonio es base de indiscutible inspiración para el Bosco y los pintores nórdicos del siglo XV. La imágenes que difunden por doquier a San Antonio Abad, fijan una iconografía reconocida mediante una serie de atributos como son la TAU (divisa de la Orden de los Monjes Antonitas), y la compañía del cerdo, animal por excelencia del santo que, como algún sector de la crítica ha visto, simboliza la lujuria y otros placeres de la carne que el santo tiene que vencer $^{12}$.

La veneración de su cuerpo surge en el Delfinado francés, lugar al que llegaron sus reliquias procedentes de Constantinopla. En el año 1095, el gentilhombre Gastón de Valloire funda una pequeña hermandad en Saint Antoine de Viennois en agradecimiento por la curación de su hijo, afectado por el entonces extraño y desconocido virus. Tras ser aprobada la constitución por el Papa Urbano II se funda ese mismo año la Orden de los Caballeros de San Antonio ${ }^{13}$ u Orden de los Antonitas, adscritos a la Regla de San Agustín y de fuerte expansión en Alemania y en los Países Bajos. Su principal misión era acoger, proteger y prestar ayuda religioso-sanitaria a los afectados por el fuego de San Antonio y, con el tiempo, a todos aquellos que, dentro de una mentalidad medieval (carente de criteriología clínica), fuesen representativos de alguna clase de epidemia, mendicidad o locura ${ }^{14}$. Los fenómenos convulsivos y

11 Para la vida de San Antonio consultar:

- Migne (1915), Patrología latina, París, col. 859-63.

- Lacarriere, J. (1964), Los hombres ebrios de Dios, cap. 3, 6584.

- GrahaM, R., «A picture-book of the life of St. Anthony, the Abbot», Archeologia, 1-26.

12 Chaumartin, H. (1930), «Le compagnon de Saint Antoine. Le symbolisme du cochon attribut caractéristique du Saint», Aesculape, 20, 233-56; p. 235.

1.3 LEISTOKOW, D. (1967), Edificios hospitalarios en Europa durante diez siglos. Historia de la arquitectura hospitalaria, Rheim, p. 45. El autor incluye a la de San Antonio entre las órdenes hospitalarias no caballerescas.

14 Cianconi, A. \& LenzI, E. (1975), «L'Ordine Ospedaliero dei Cavalieri del Tau», Rivista di Storia della Medicina, 1, 98-111; p. 110. Los autores consideran que la orden de la TAU se dedicaba a acoger no sólo a los enfermos de ergotismo, sino también a prostitutas, madres solteras, peregrinos y personajes juglarescos. Creen que veneraban a San Jacopo y que simultaneaban las funciones de clérigos y de soldados. 


\section{EL FUEGO DE SAN ANTONIO: ESTUDIO DEL ERGOTISMO EN LA PINTURA DEL BOSCO}

gangrenosos, hacían que el clima médico de la época, preñado de supersticiones, considerase «loco» a quien presentaba estos cuadros clínicos, pues no hay que olvidar que la admisión en los monasterios-hospitales de los antonitas recaía en manos de sus monjes, carentes de adecuada formación médica. Será el siglo XVI quien enfoque convenientemente estos criterios de distinción entre el incurable y el indigente como Juan Luis Vives (1492-1540) hará por medio de sus obras De Subventione Pauperum o de su Tratado del Alma ${ }^{15}$. Entre los síntomas que equivocadamente conducían a pensar en el enfermo de ergotismo como un perturbado, se halla la tendencia a la tristeza, a lo irreal, que identificaba así al afectado con el melancólico. André Chastel ${ }^{16}$ basa esta idea en el hallazgo de un manuscrito de la biblioteca de Tubingia (fig. 7) en la que aparece un monje con la divisa TAU simbolizando al planeta Saturno, planeta que representa al cuarto humor, que es el que se corresponde con la melancolía. Los llamados hijos de Saturno en tiempos medievales eran los locos, mendigos y abandonados de toda suerte, así como los filósofos, místicos y eremitas. El tutelaje astrológico que el planeta ejercía sobre todos ellos sería el equivalente -siguiendo la particular interpretación que hace Chastel- al tutelaje que San Antonio ejercería también sobre sus marginados y enfermos.

Al margen de concepciones medievales, debemos al Renacimiento el esclarecimiento científico de la enfermedad. En principio, se distingue el ergotismo del mal de los ardientes (identificado con la peste bubónica) y de la sífilis (llamada en algunos textos el fuego blanco, por la tonalidad de sus úlceras). En el año 1597 la Facultad de Medicina de la Universidad de Marburgo redacta un tratado en el que se describe lo que era la «Kriebelkranheit» o enfermedad del hormigueo, es decir, el ergotismo ${ }^{17}$. Estudios médicos posteriores llevan a Dodart a observar en el año 1676 que la gangrena era provocada por la absorción del centeno «atizonado», o por el ya mencionado hongo claviceps Purpurea. En el año 1776 la Societé Royaux de Médecine de París establece la diferenciación entre el ergotismo convulsivo y el gangrenoso. Un siglo más tarde (1884), se descubren los agentes indirectos que atacan: la cornutina para el modelo convulsivo y el ácido sphacélico en los vasos sanguíneos, que deriva finalmente en gangrena. Ya en nuestro siglo la ergotamina es aislada del cornezuelo de centeno por Stoll (1918), por lo que son rarísimos los casos hoy en día de intoxicación por cornezuelo ${ }^{18}$. Sus alcaloides quedan clasificados, globalmente, de la siguiente manera:

\footnotetext{
15 Vives, J. L. (1947-1948), Madrid, Obras Completas.

16 CHASTEl, A. (1978), «La tentation de Saint Antoine ou le songe du mélancolique», Fables, Formes, Figures, Paris, vol. 1, 137-46.

17 MARine, A. (1970), «Cornezuelo y ergotismo», Miscellánea Barcinonensia, Revista de Investigación y Alta Cultura, 27, 7-27; p. 17.

18 BRABANT (1967), p. 96.
} 


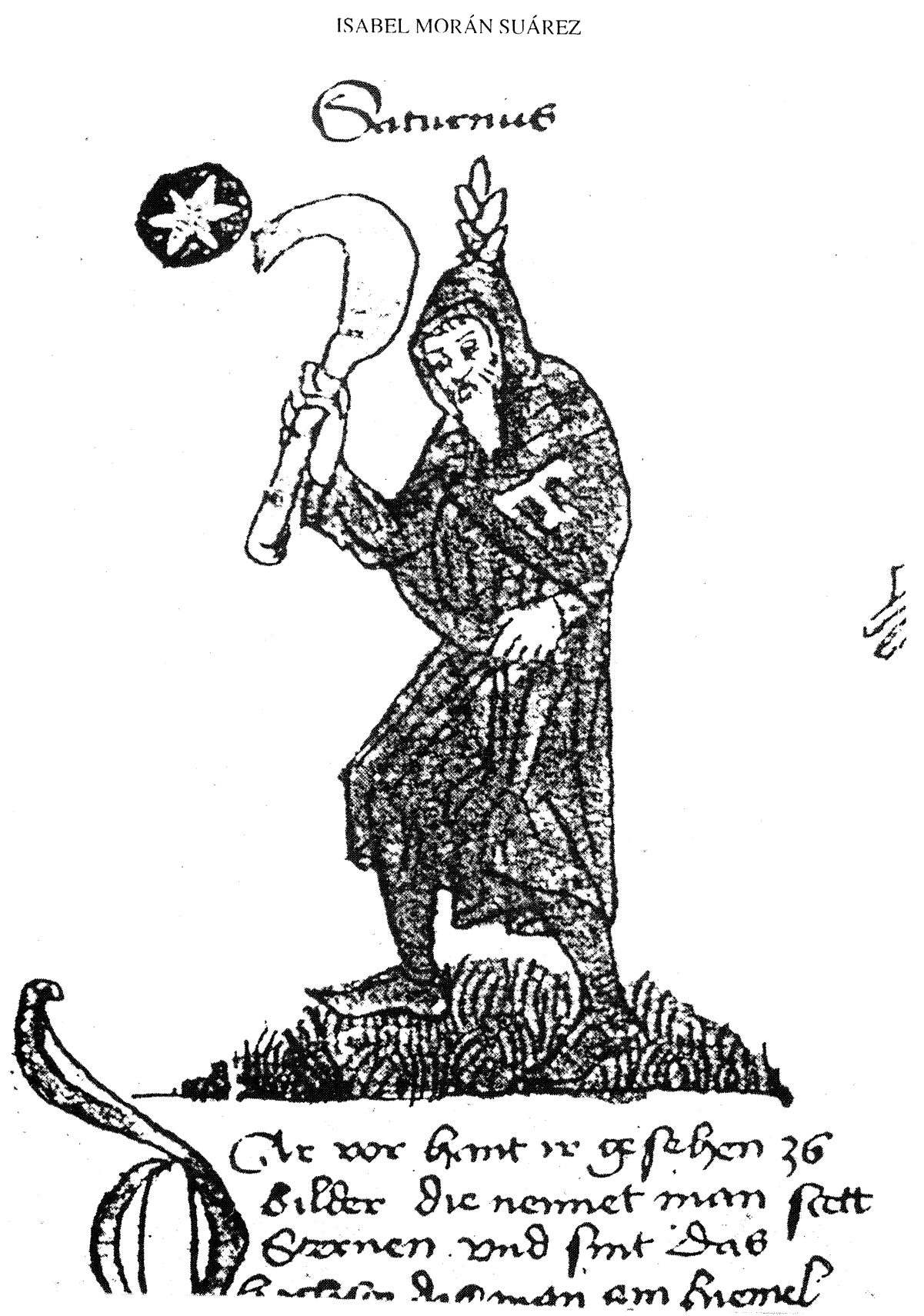

Fig. 7.- El Planeta Saturno. Miniatura extraída del Manuscrito datado 1404, Biblioteca de la Universidad de Tubingia. 

A) Alcaloides naturales.
B) Alcaloides hidrogenados.
C) Alcaloides y derivados semisintéticos y sintéticos.

Por estar consagrado explícitamente a la figura de San Antonio y sus enfermos, es el de Isenhein el más destacado de todos sus monasterios. En sus orígenes actuó como centro de acogida de sifilíticos, puesto que el brote del año 1490 fue devastador para la población ${ }^{19}$. El retablo del famoso altar (actualmente en el museo de Unterlinden en Colmar, Francia) fue pintado por Matías Grünewald durante los años 1508-1516. En dicho retablo, el doctor García de Yébenes ${ }^{20}$ considera muy probable que Grünewald utilizara como modelos para sus pinturas a pacientes con ergotismo crónico. Esta tesis, que refuerza la teoría de Quinn²1 ${ }^{21}$ cree que la distonía es una manifestación clínica de los pacientes con ergotismo epidémico. No sólo en dicho altar, sino en el tapiz de San Antonio o en la tabla del museo de Valenciennes (véanse figs. 2 y 4) se reflejan enfermos con idéntico debilitamiento muscular lo que constataría que la distonía es una característica de los enfermos de ergotismo.

En el retablo de Isenheim aparece un enfermo (fig. 8) de dudosa interpretación. ¿Podría tratarse de una tuberculosis cutánea, de una sífilis tardía o gomosa?. ¿O no sería más lógico que aludiese a un enfermo del «mal de San Antonio»? Ante dicho altar, acudían en peregrinación todos aquellos afectados por diversas plagas que deseaban fervientemente curarse, por lo que se especuló que el altar pudiera desempeñar, en una doble lectura, un papel preventivo o terapéutico. A esta sugerente interpretación se han sumado otros autores, como Cinotti entre ellos ${ }^{22}$, que piensa que el tríptico de Lisboa - también consagrado a la figura de San Antonio y sus tentaciones (Fig. 9) - desempeñase una función semejante. En la tabla central el santo se gira y mira directamente al espectador (en su supuesto caso, al enfermo que lo contemplaba) con idéntica intención de curar al enfermo. De admitir esta teoría, quedaría justificada la proliferación de cuadros dedicados al tema de San Antonio ${ }^{23}$ por su carácter preventivo. Su posterior instalación en monasterios o en casas de sus afectados, ¿no sería el reflejo de los estragos y el pánico que la enfermedad causó, y que

19 FreY, E. (1979), «Saints in Medical History», Clio Medical, 14, 52-4; p. 53. Consultar también: Ciba Sociedad Anónima de Productos Químicos (1948), Santos Sanadores, Barcelona.

20) García de YÉbenes, J. (1991) «La distonía en la pintura de Matías Grünewald. El ergotismo epidémico en la Baja Edad Media», Archivo de Neurobiología, 54, 2, 37-40, p. 40.

21 QuinN, N. (1983), «Dystonia in epidemic ergotism», Neurology, 33, p. 1267.

22 CinotTi, M. (ed. esp. 1992), La obra completa de El Bosco: Ha. 1450- 1516, Barcelona, p. 81.

2.3 BANGO, I. \& MARíAS, F. (1982), Bosch: símbolo, realidad y fantasía, Vitoria, p. 204. Los autores dicen que de las treinta y cuatro obras del Bosco (entre obras autógrafas y copias) que tratan el tema de los santos, en veintidós ocasiones el protagonista es San Antonio. 


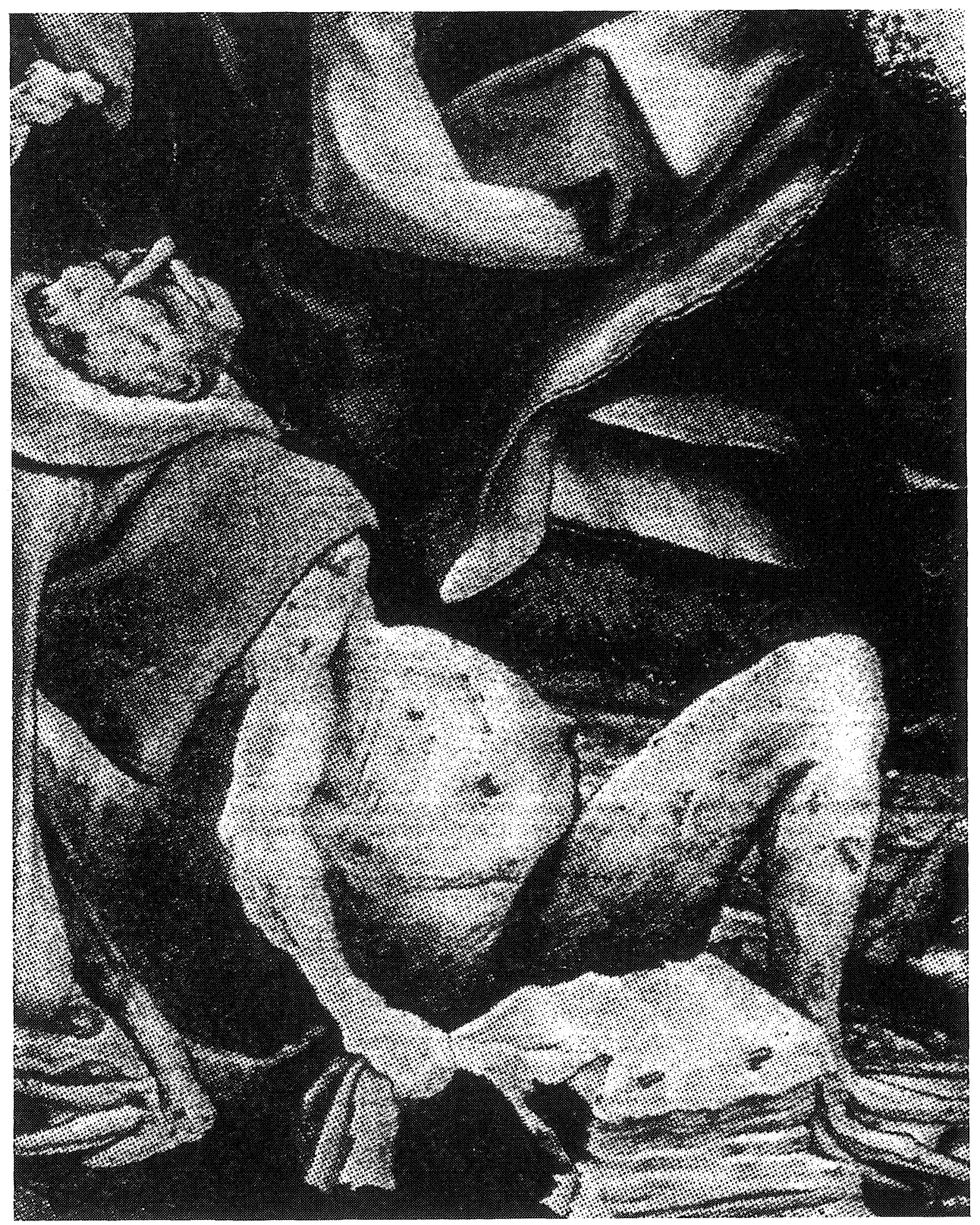

Fig. 8.- Matías Grünewald. Retablo del Altar de Isenheim Unterlinden Musseum, Colmar Det. Enfermo. 

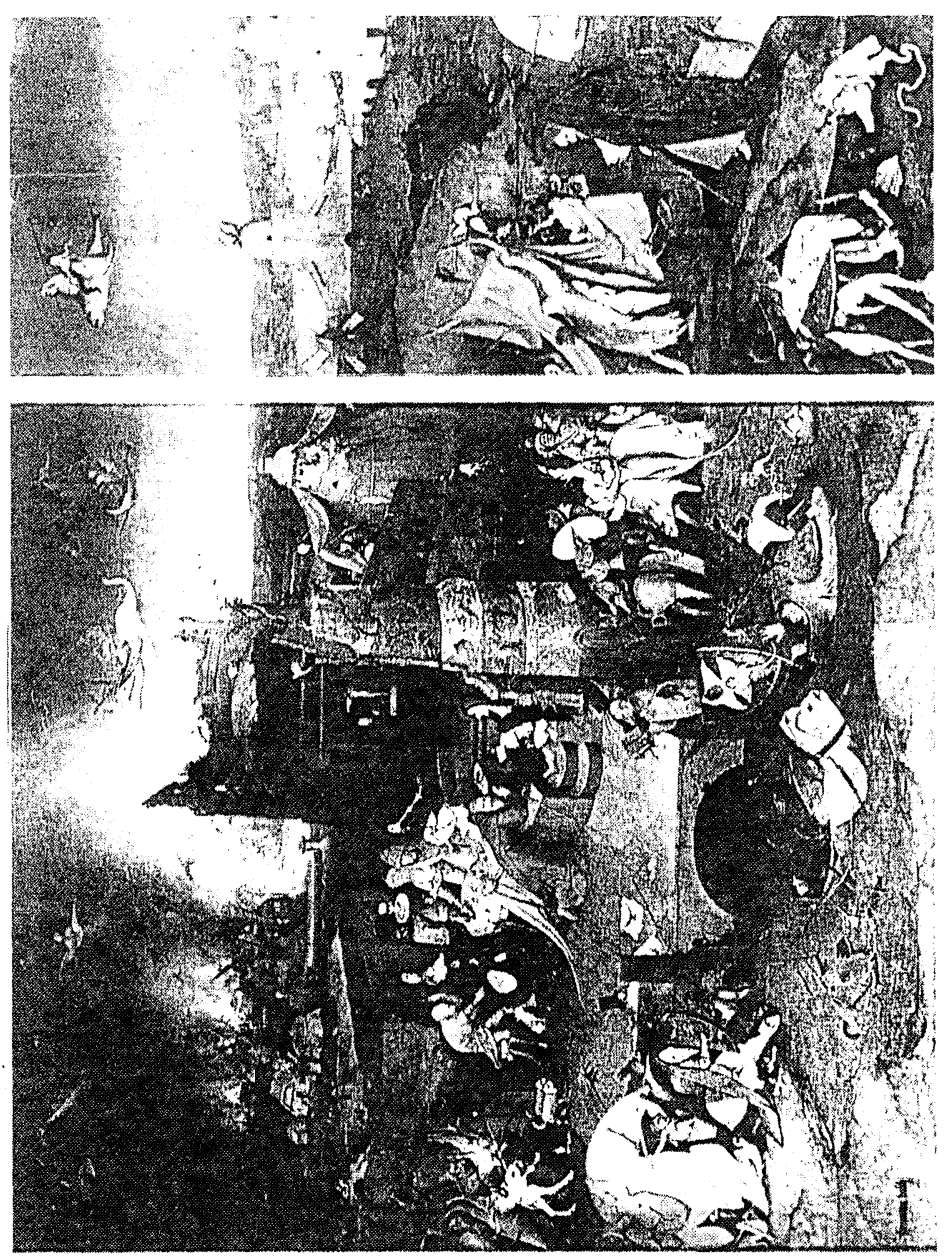

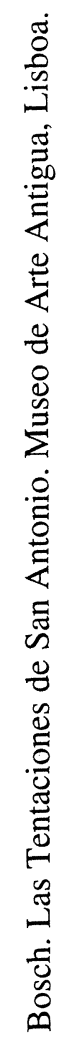

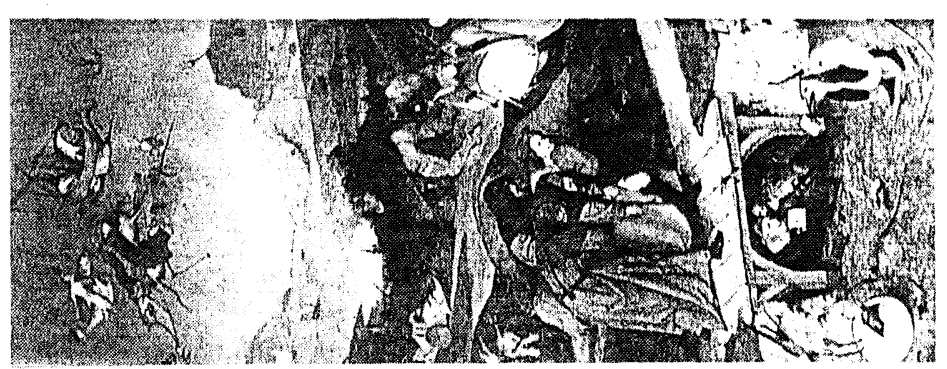

I

$\sigma$

定 
provocaría la demanda de cuadros del santo titular?24 Además, esta idea de contemplación de los cuadros como remedio o antídoto ante la enfermedad, ¿no supone, implícitamente, el reconocimiento de la Iconoterapia? Si aceptamos las teorías de Donadio ${ }^{25}$, en el proceso de curación del enfermo de ergotismo se advertían dos fases:

A) La diagnosis y el tratamiento de la enfermedad.

B) Contemplación del altar para sanar y extinguir la enfermedad.

Por esta razón, enfrente del altar de Isenheim estaba el cuadro de la Tentaciones de San Antonio para ser contemplado y cuya leyenda en latín rezaba: «Ubi eras, Ubi eras quare non affuisti ut sanare vulnera mea? $\gg^{26}$.

Al margen de este tipo de reflexiones, muy sujetas al papel simbólico que el arte tenía y a la mentalidad que la sustentaba, existían una serie de procedimientos resolutivos que trataban de poner fin práctico a la enfermedad. Un brebaje que se bautizó como el agua de San Antonio, tenía poderes curativos, por lo que, distribuido primero gratuitamente y más tarde vendido en las abadías, constituyó uno de sus remedios. Los panes de San Antonio, realizados desde el siglo XI y hechos con una harina especial y pura de centeno, son consumidos incluso en la actualidad el día de la celebración de San Antonio (17 de enero) en Alemania. La manteca de cerdo ${ }^{27}$, considerada milagrosa, era untada sobre los organos afectados, paliando parte de la infección. Se especuló con el cerdo de San Antonio, hasta el extremo de gozar de privilegios especiales, como el de poder deambular libremente sin ser dañado o robado por las calles de las ciudades. La comunidad antonita lo protegía sin límites, pues veía en dicho animal una importante fuente de ingresos. Así nos lo confirmá Rabelais:

\footnotetext{
«Poco después vino un Mayordomo Jamonero de los de San Antonio a hacer su puerca colecta.... ${ }^{28}$.
}

Pero de todos los remedios curativos, tal vez sea el del Santo Vino el más célebre. Se forjó una leyenda sobre el Santo Vino, vino que se cultivaba en las propias viñas

\footnotetext{
24 Chavant, M. (1913), «Extraits choisis sur le Feu de Saint Antoinc", XVIlth International Congress of Medicine, London, 87 96; p. 87.

25 DONADIO, E. (1985), «Painting for patients. Grunewald's Isenheim Altarpiece», Medical Heritage, $l, 448-54 ;$ p. 452.

26 «¡Oh Jesús! ¿Dónde estabas, dónde estabas, que no acudiste a sanar mis heridas?»

27 ChAumarTin (1930), p. 238.

28 RABELAIS (1992), p. 100.
} 
del monasterio y que era elaborado con parte de las consideradas reliquias del santoeremita, fermentadas en alcohol. La ingestión de tal brebaje fue considerado el verdadero antídoto contra el fuego de San Antonio, surgiendo pronto falsas imitaciones o ventas ilegales. Tal efecto llevó al Papa Sixto IV a declarar en el año 1473 que el Santo Vino solamente se debía de administrar en la casa madre. Cuttler ${ }^{29}$ piensa que la escena central del tríptico de Lisboa representa la escena del Santo Vino en medio de la celebración del sabbath, claro exponente del clima herético que se apoderó de los siglos finales del medievo.

Finalmente, la mandrágora, ya descrita por el doctor Laguna como «una planta cuyas raíces parecen útiles a los hechizos» ${ }^{30}$, mezclada con el vino milagroso servía para reforzar los poderes curativos de la pócima de San Antonio, según Jacques van Lennep $^{31}$. Es más probable admitir el uso de la mandrágora como anestésico, ya que durante las operaciones practicadas en el medioevo era común el uso de la llamada esponja soporífera, que el profesor Laín nos la describe como empapada previamente de opio, jugo de moras amargas, beleño, euforbio, MANDRÁGORA, hiedra y semillas de lechuga ${ }^{32}$. Para dichas prácticas quirúrgicas, acudían ex-profeso los cirujanos laicos contratados por los antoninos, ya que a partir del Concilio de Clermont (1130) se prohibió ejercer la medicina a los clérigos ${ }^{33}$. El libro L'Epitome, redactado por Guy Didier e impreso en el año 1500, fue el primer tratado de cirugía para los enfermos de ergotismo, nombrado en los textos como fuego de San Marcial, y cuya cirugía era aconsejada como el remedio más eficaz. Dichas intervenciones quirúrgicas favorecieron, sin pretenderlo, un extraordinario fomento de la mendicidad ya que el desmembrado llevaba consigo el miembro amputado para dar lástima a las almas generosas (fig. 10). La exposición de ex-votos colgados a las puertas de los monasterios llegó a ser un símbolo externo que apelaba a las conciencias cristianas (fig. 11). Se potenció, desde los mismos centros monásticos, la mendicidad tal y como lo corroboran las palabras del Abad J. Joguet:

«...que unos y otros lleven sus vestidos de manera que se haga evidente para que el pueblo sea inducido a una mayor devoción, compasión y reverencia hacia San Antonio.»3.4.

\footnotetext{
29 CUTTLER, CH. (1957) «The Lisbon Temptation of St. Anthony by Jerome Bosch», The Art Bulletin, 39, 109-26; p. 118.

30) Laguna, A. (ed. fasc. 1992), Dioscórides, Madrid, p. 243.

31 VAN LENNEP, J. (1968), «Le feu et la Mandragore. À propos de la tentation de S. Antoinc par J. Bosch», Bulletin des Musées Royaux des Beaux-Arts de Belgique, 17, 115-36; p. 129.

32 LAÍN (1972), p.315.

33 LAíN (1972), p. 154.

34 Loc: cit. nota 31, p. 122, Extracto de un viaje literario por diez religiosos benedictinos de la Congregación de San Maur, dom Martene y dom Durand, I, París, 1717.
} 


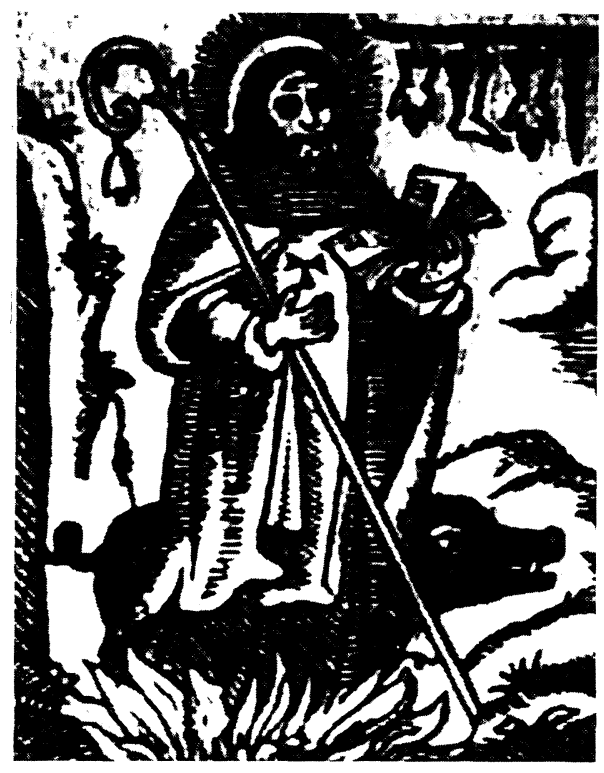

Fig. 10.- Grabado anónimo S. XV. San Antonio Abad. Welcome Institute, Londres.

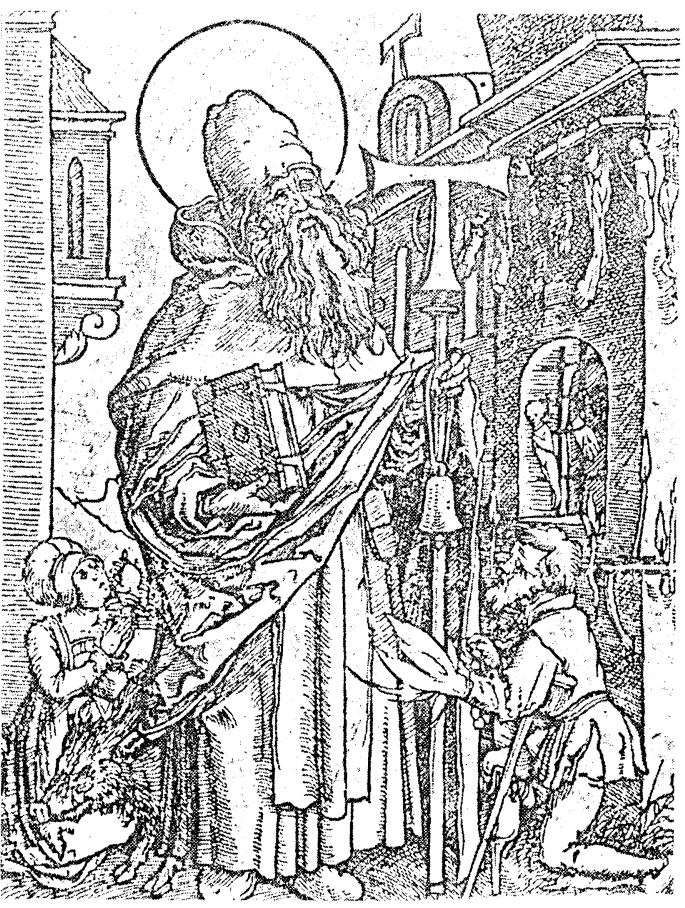

Antonio invocado por los enfermos del Mal de los Ardientes. 
Actitud que contó con el respaldo tácito de la Sede Pontificia dado que papas como Inocencio VI o Clemente VI jamás lo prohibieron. Ambrosio de Paré ${ }^{35}$ nos cuenta cómo los «supuestos» enfermos simulaban úlceras o se automutilaban para obtener a cambio unas limosnas que les permitieran sobrevivir maltrechamente. Incluso, se llegó a seccionar miembros a los ahorcados para hacerlos propios y así conmover a la piedad o también para que estos órganos profanados fueran objeto de ventas ilegales.

Referente a los órganos desmembrados, el pie cortado es uno de los elementos más reiterado en los cuadros del Bosco, pues aparece en varias obras del Bosco, como en el Jardín de las Delicias, en un detalle de la tabla central del tríptico de Lisboa (fig. 12) o en el tapiz de la marcha de San Antonio de la ciudad. Muchas han sido las interpretaciones que sobre los órganos desmembrados como pies, manos o brazos se han ofrecido desde diversos enfoques. Van Lennep ${ }^{36}$, siguiendo a Combe, cree que se trata de un elemento de la alquimia, tan en boga durante la Edad Media, que veía en el pie cortado la fijación del mercurio, elemento femenino de la Gran Obra Alquímica. José Luis Bermejo ${ }^{37}$ piensa que el pie cortado representa la penalización jurídica por un castigo o falta cometida, recogido ya en los Fueros Juzgos, mientras que Isabel $\mathrm{Mateo}^{38}$ cree más probable que aluda a la venta de falsas reliquias, base de las peregrinaciones durante toda la Edad Media, incluso en los mismos centros de los monjes antonitas. Por último, existe también una visión más psicológica en cuanto a la interpretación de los órganos seccionados. El profesor Escudero Valverde ${ }^{39}$ aduce como uno de los rasgos de la pintura esquizoide la fragmentación de órganos humanos. El crítico de la obra del Bosco, Gauffreteau-Sévy ${ }^{40}$ ha hallado en estas mutilaciones el símbolo de la angustia latente que existía en el Bosco, angustia producida bien por el contexto desquiciante de la época o bien por una anomalía de su personalidad. Ello ha hecho que el Bosco y su compleja obra atrajesen siempre la atención médica, motivo por el cual se llevó a cabo un ciclo de conferencias en el Colegio de Médicos de Madrid en el año 1957, y cuyas impresiones expuestas acerca de la obra del Bosco fueron recogidas por Isabel Mateo ${ }^{41}$.

\footnotetext{
35 PARe, A. (1840-41), Oeuvres completes, París, III, p. 46.

36 VAN LENNEP, J. (1978), Arte y alquimia, Madrid, 221-32.

37 Bermejo, J. L. (1971), «Sobre el pie cortado del Jardín de las Delicias del Bosco», Boletín del Seminario de Arte y Arqueología de Valladolid. 37, 479-81; p. 480.

38 MATEO, I. (2. ${ }^{a}$ ed. 1991), El Bosco en España, Madrid, p. 25.

3) Escudero, J. A. (1975), Pintura psicopatológica, Madrid, p.76.

40) Gauffreteau-Sevy, M. (1973), Hieronymus Bosch «El Bosco», Barcelona, 1973, p. 131. La opinión unánime de la crítica autorizada descarta una presunta personalidad desviada en la figura del Bosco. Su vida así lo testifica.

41 Mateo, I. \& Guillaud, J. M. (1988), Jerónimo Bosco. El Jardín de las Delicias (1988), París, pp. 24-5.
} 
ISABEL MORÁN SUÁREZ

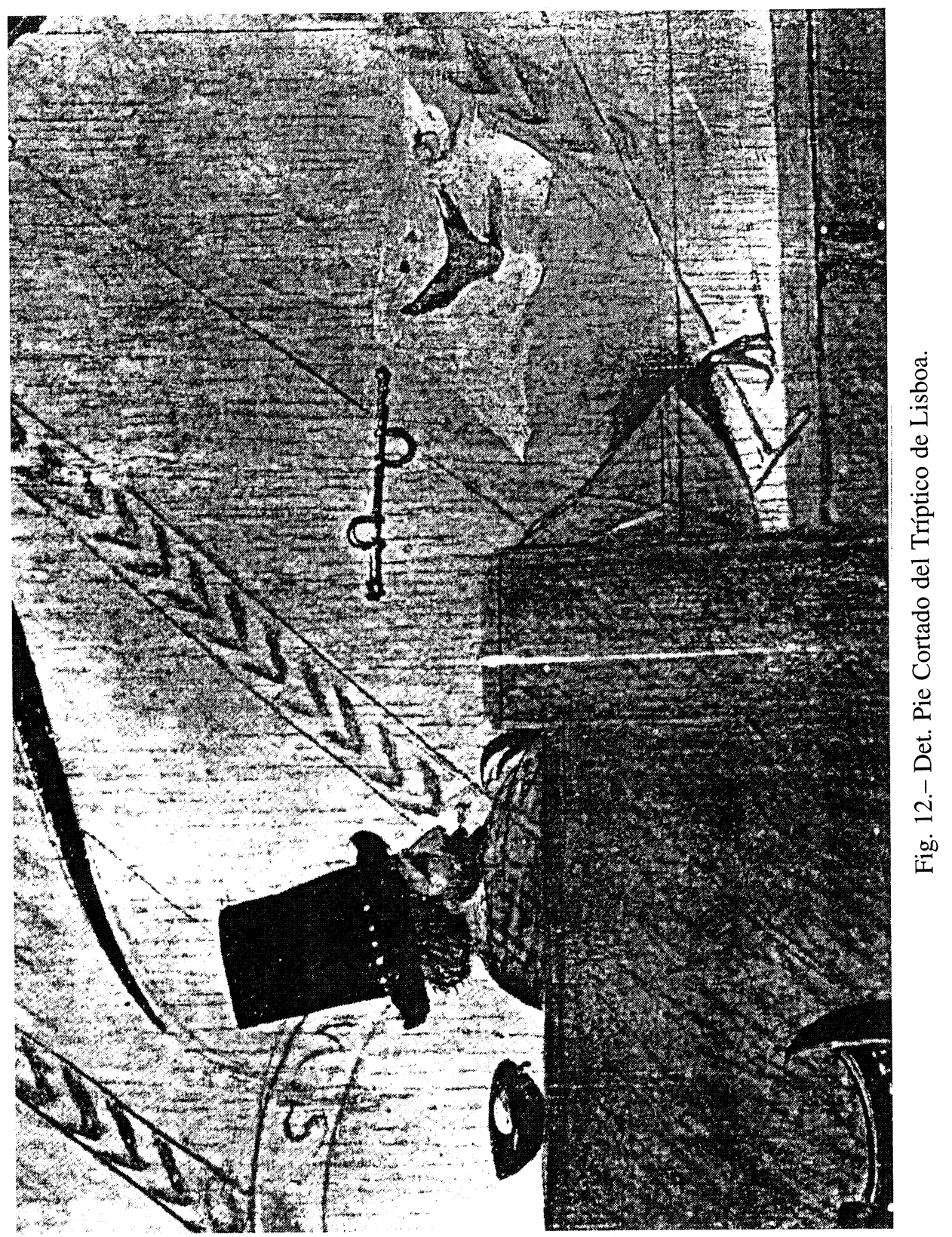

192

Asclepio-Vol. XLVIII-2-1996 
Actualmente, y a partir de los pioneros estudios realizados por Dale en el presente siglo, sabemos que existe una medicación ergotínica, cuya posología, administrada convenientemente, es recomendable para la contención de hemorragias uterinas, período de alumbramiento, hipertensión, o para las cefaleas, pues la ergotamina es básica para el tratamiento contra las migrañas ${ }^{42}$. Pese a que la ergotamina ofrece un rendimiento a la industria farmacológica, se puede llegar a una intoxicación por una inconveniente o excesiva medicación ${ }^{43}$.

Finalizaremos retomando el dibujo autógrafo del Gabinete de Estampas de Bruselas, del que partimos al inicio. Podríamos concluir diciendo que sus personajes representados son un claro exponente de enfermedad identificada como el ergotismo. Dichos pacientes, auxiliados con apoyos para sus desplazamiento, constituyen «todo un tratado gráfico de prótesis y ortopedia práctica retrospectiva» ${ }^{44}$. Los enfermos del fuego de San Antonio son algo más que personajes que dan vida al tema de las tentaciones de San Antonio en la pintura de los primitivos flamencos. Detrás del culto a la figura de San Antonio, sus enfermos cobran un protagonismo propio, desde una doble vertiente: la social, que denuncia la marginalidad de estos individuos, y la científica que empieza seriamente a interesarse por su estudio. El Bosco, crítico implacable de su época y sensible a la conciencia popular, retrata no sólo física, sino psicológicamente, a enfermos de ergotismo y otras plagas, a tullidos y mendigos de una Europa medieval sumida en el más profundo miedo a la muerte.

\section{AGRADECIMIENTO}

Quiero expresar mi sincero agradecimiento al doctor González y López por impulsar mi iniciativa hacia el presente artículo y, especialmente, al doctor García de Yébenes por la revisión de los conceptos clínicos que en él expongo. A ambos, su tiempo y su atención.

42 VelázQuez (1993), p. 151. \& HARrison (ed. 13a 1994), Principios de Medicina Interna, Madrid, p. 79.

4.3 MARAÑón, G. (ed. 13 13 1984), Manual de Diagnóstico Etiológico, Madrid, p. 84

44 «Lisiados, mancos y tullidos», Arte y patología. Artículo facilitado por la doctora Mateo Gómez. En la publicación no se detalla ni el autor, ni el año, ni el número en que fueron publicados. 